\title{
Defesa internacional contra as doenças epidémicas: Da visão de Jules Héricourt
}

\author{
International defense against epidemic diseases: \\ From Jules Héricourt's view
}

\author{
Jorge Bonito, \\ CIEP da Universidade de Évora e CIDTFF da Universidade de Aveiro (jbonito@uevora.pt)
}

\begin{abstract}
Resumo: As doenças epidémicas que assolaram as populações europeias vieram juntar-se às misérias já existentes até meados do século XIX, provocando consideráveis perdas de vidas humanas. O continente europeu tem uma longa história com a peste, doença causada pela bactéria $Y$. pestis. Ao contrário do que se possa pensar, a peste bubónica não é uma doença do passado. Continua presente em mais de uma dezena de países do mundo. Este artigo analisa as ideias de Jules Héricourt relativamente à transmissibilidade internacional das doenças epidémicas e o modo de mitigar as suas cadeias. Apoia-se, na essência, na sua obra Les Frontières de la Maladie, nomeadamente na Défense internationale contre las maladies épidémiques, et systémes quarantenaires. Em 1901, um surto de peste assolou os passageiros e a tripulação do navio Senegal, num cruzeiro no Mediterrâneo. Foi imposta uma quarentena a toda a tripulação e aos 174 passageiros no lazareto do arquipélago francês de Frioul. Registou-se uma morte. A falta de serviços mínimos e de medidas de desinfeção imediata dos passageiros e dos respetivos pertences poderia ter agudizado o problema. Héricourt, médico coautor da seroterapia, discorda dos métodos adotados pelas autoridades sanitárias, que seriam ilusórios na defesa internacional contra as doenças epidémicas. $\mathrm{O}$ autor propõe uma dupla solução prática e eficaz para o problema da transmissão das doenças exóticas nas viagens marítimas: a valorização do passe sanitário e a modificação do papel do médico de bordo. Todos os passageiros provenientes de territórios contaminados deveriam ser portadores do passe sanitário, sob rigoroso controlo das autoridades. Ao médico de bordo caber-lhe-ia constituir-se como verdadeiro agente da administração sanitária, como higienista, desmascarando potenciais doentes a partir de exames médicos durante a viagem e evitando que passageiros dados como sãos contaminassem a comunidade, por estarem efetivamente doentes.
\end{abstract}

Palavras-chave: Héricourt, peste bubónica, controlo sanitário, médico de bordo, passe sanitário

Abstract: The epidemic diseases that devastated the European populations added to the
miseries that existed until the mid-nineteenth century, causing considerable loss of human
life. The European continent has a long history of plague, a disease caused by the Y. pestis
bacteria. Contrary to popular belief, bubonic plague is not a disease of the past. It is still
present in more than a dozen countries around the world. This paper analyzes Jules
Héricourt's ideas regarding the international transmissibility of epidemic diseases and how
to mitigate their chains. It is essentially based on his work Les Frontières de la Maladie,
namely on Défense internationale contre les maladies épidémiques, et systémes
quarantenaires. In 1901, an outbreak of plague ravaged the passengers and crew of the ship 
Senegal on a Mediterranean cruise. A quarantine was imposed on the entire crew and 174 passengers in the lazaretto in the French archipelago of Frioul. There was one death. The lack of minimum services and immediate disinfection measures for passengers and their belongings could have exacerbated the problem. Héricourt, physician, co-author of the serotherapy, disagrees with the methods adopted by health authorities, which would be illusory in the international defense against epidemic diseases. The author proposes a practical and effective double solution to the problem of the transmission of exotic diseases in sea voyages: the enhancement of the health pass and the modification of the role of the doctor on board. All passengers from contaminated territories should carry a health pass, under strict control by the authorities. The on-board doctor is responsible for establishing himself as a true agent of the health administration. As a hygienist, he unmasks potential patients, based on medical examinations during the trip, and prevents passengers who are considered healthy from contaminating the community, as they are effectively ill.

Keywords: Héricourt, bubonic plague, health control, onboard doctor, health pass

\section{Introdução}

Jules Héricourt ${ }^{1}$ (1850-1938) nasceu no seio de uma família operária. Por intermédio de intenso trabalho e graças ao sacrifício da sua mãe, ingressou na École Impériale du Service de Santé Militaire de Strasbourg, em França. Formado em medicina, apaixonou-se pela microbiologia na década de 1880, libertando-se da tutela dos seus mestres Paul-Louis André Kiener ${ }^{2}$ (1841-1895) e Achille Louis Félix Kelsch ${ }^{3}$ (1841-1911), contribuindo, por intermédio da sua teoria das doenças atenuadas (maladies atténuées) para a consolidação da teoria dos germes de Pasteur (1822-1895) (Monet, 2018).

Durante os primeiros anos de exercício, Héricourt demonstrou um interesse marcante pela higiene e, acima de tudo, distinguiu-se pela recusa das injustiças e pela preocupação constante pelos mais desfavorecidos, assumindo com coragem a defesa dos soldados comuns. O seu amigo de colégio Charles-Robert Richet (1850$1935)^{4}$ convida-o para trabalhar ao seu lado no Laboratório de Fisiologia da

\footnotetext{
${ }^{1}$ A sua fotografia foi publicada num artigo de sua autoria, em 1914 (Héricourt, 1914, fev.).

${ }^{2}$ P.-L. Kiener estudou em Estrasburgo. Trabalhou nos hospitais de Lyon e na Faculté de Médecine de l'Université de Strasbourg. Foi médico-chefe da Província Constantine e professor no Hôpital d'Instruction des Armées du Val-de-Gâce. Médico principal da Armada e diretor do serviço de saúde dos 16 corpos do exército. Por último, foi professor de anatomia patológica da Faculté de Médecine da Université de Montpellier, França (Whonamedit, 2021).

${ }^{3}$ Médico principal da Armada. Professor da École de Médecine et de Pharmacie Militaires do Hôpital d'Instruction des Armées du Val-de-Gâce, Paris, França. Com P.-L. Kiener, publica, em 1889, Traité des maladies des pays chauds: région prétropicale.

${ }^{4}$ Richet era discípulo de Claude Bernard (1813-1878) e herdeiro da Escola Francesa de Fisiologia. Médico e professor de fisiologia na Universidade de Paris, viria a receber o Prémio Nobel de Fisiologia ou Medicina em 1913, pelo seu trabalho sobre anafilaxia (Nobel Prize, 2021).
} 
Faculdade de Medicina. Héricourt trouxe-lhe valiosos conhecimentos e um saber fazer precioso no campo da microbiologia (Androutsos, Karamanou, Stamboulis, Liappas, Lykouras, \& Papadimitriou, 2011; Daguet \& Watier, 2011).

Héricourt e Richet, em 1888, destacaram o papel do organismo na imunidade, descrevendo o princípio da seroterapia, fazendo as experiências com o soro de cão vacinado contra Staphylococcus, uma revolução terapêutica no final do século XIX. Decidiram, porém, por insistência de Héricourt, aplicar a seroterapia a uma "doença social" que estava a devastar os pobres: a tuberculose.

Em 1890, Héricourt explica o método geral para conferir imunidade: "En transfusant à un animal susceptible d'infection le sang d'un animal réfractaire, on rend le transfusé réfractaire à son tour comme l'était le transfuseur lui-même" (Marie, 2015, p. 18). Em dezembro desse ano, Richet aplica, pela primeira vez, seroterapia a um ser humano.

Após dois anos de pesquisas infrutíferas, o alemão Emil Adolf von Behring (1854-1917), colaborador de Robert Koch (1843-1910), com o japonês Kitasato Shibasaburo, desenvolveram com sucesso a seroterapia para a difteria, sendo atribuído a Behring o Prémio Nobel da Fisiologia ou Medicina em 1901. Stewart Wolf, na sua biografia de Charles-Robert Richet, publicada em 1993, relata uma velha disputa que opôs E. von Behring a Richet, ambos alegando ter sido o primeiro a criar a seroterapia. Richet e Héricourt descreveram a hematoterapia, mas a sua descoberta nunca foi estudada em detalhe nem o contexto em que tal ocorreu. Richet e, possivelmente, Héricourt podem ser vistos como atores, daquilo que o historiador da medicina francês Jacques Léonard (1935-1988) chamou, usando um neologismo, de um movimento de "fisiologização do pasteurismo", quando os físiologistas ingressaram no campo da bacteriologia na década de 1880, o que levou ao nascimento da imunologia (Lahaie \& Watier, 2017).

Depois destes insucessos na busca da seroterapia anti-tuberculose, Héricourt e Richet, em 1895, tentaram aplicar este método a várias doenças, em particular, realizando os primeiros ensaios de seroterapia de combate ao cancro, prenunciando as atuais imunoterapias (Daguet \& Watier, 2011).

Em 1898, Héricourt é arrolado como testemunha no julgamento de Émile Zola (1840-1902). Revoltado com a injustiça sofrida no caso Dreyfus, foi um dos primeiros intelectuais, na esteira de Émile Duclaux (1840-1904), e sob os auspícios do "espírito científico", a levantar-se em defesa do judeu capitão ${ }^{5}$. No ano seguinte,

\footnotetext{
${ }^{5} \mathrm{O}$ seu compromisso Dreyfusardo rapidamente se transformou num compromisso "dreyfusista" mais amplo, que ficou expresso pela sua ação no interior da Ligue des droits de l'Homme (LdH), da qual Héricourt foi um dos fundadores em 1898. A partir de 1904, após ter procurado um novo rumo político, ao participar da formação da Alliance Républicaine Démocratique, em 1901, Héricourt é eleito vicepresidente da $L d H$, juntando-se a Francis de Pressensé (1853-1914) na luta pelo reformismo social (Monet, 2018).
} 
publica-se La Sérothérapie - Historique, état actuel, biblliographie, no seu dizer, um "capítulo" da história da medicina, obra dedicada, em dezembro de 1898, a Charles Richet "Cher Ami, puisque tu m'as associe aux travaux dont ce livre rappelle l'origine et montre de développement, laisse-moi inscrire ton nom à cette première page, pour dire ma reconnaissance et notre vieille amitié” (Héricourt, 1899, p. V).

Héricourt, fisiologista e doutor em medicina, deixou de lado cargos de maior prestígio, por exemplo, optando por ser diretor do Dispensaire-sanatorium Jouye Rouvre-Taniès, em Paris, e médico inspetor dos correios, por ser um ator da higiene social que defendia nos seus trabalhos escritos e por se dedicar aos pobres e à tuberculose, uma doença que os atormentava. Foi chefe-adjunto do Laboratoire de Physiologie de la Faculté de Médecine de Paris (Watier, 2009).

Em 1904, Héricourt escreve Les Frontières de la Maladie: Maladies Latentes et Maladies Atténuées ${ }^{6}$, colocado na Bibliothèque de Philosophie Scientifique ${ }^{7}$, sob a direção de Gustave Le Bon ${ }^{8}$, publicado na editora de Ernest Flammarion (18461936), com nome homónimo 9 . O autor, na resenha temporânea de Hewlett (1904), dedica-se aos casos em que a fronteira entre a saúde e a doença não é definida, passando-se insensivelmente de um estado a outro. Trata-se de uma obra organizada em livros e capítulos. Estes, em número de 24, incluem-se nos 6 livros, a saber: os primeiros índices das doenças da nutrição (7 capítulos), as intoxicações iniciais (2 capítulos), as formas atenuadas das doenças microbianas crónicas (4 capítulos), as formas atenuadas das doenças microbianas agudas (4 capítulos), as formas evasivas das doenças pestilentas (3 capítulos), e deduções teóricas e práticas da noção de doenças atenuadas (4 capítulos), num total de 267 páginas.

Héricourt elaborou cerca de 50 trabalhos em 164 publicações, publicados em 3 línguas, estando em 450 acervos da biblioteca WorldCat (2021). Foi membro da Société de Biologie e laureado da Académie de Médecine (Prix Louis, Sérothérapie, 1898).

Em 1926, em Portugal apresenta-se uma tese de doutoramento sobre a seroterapia específica da febre tifoide, invocando-se o trabalho de Héricourt (Saraiva, 1926) mas, apesar do seu caminho e contributo para a história da medicina, Héricourt esteve quase esquecido nas décadas que se seguiram. É somente em 2007, como parte das suas primeiras pesquisas sobre a origem da

\footnotetext{
${ }^{6}$ A obra teve 29 edições publicadas entre 1904 e 1920 em francês e castelhano, mantida em 82 bibliotecas membros do WorldCat em todo o mundo (WorldCat, 2021).

${ }^{7}$ Cfr. Marpeau (2010), para mais detalhes sobre esta coleção.

${ }^{8}$ Le Bon veio, nesta coleção, a escrever um livro com o título Psychologie de l'Éducation.

${ }^{9}$ Flammarion instalou-se na Rue Racine, 26, quartier de l'Odéon, Paris, França. O edifício, reformado na década de 1980 pelo arquiteto Jean-Michel Wilmotte, tornou-se, ao longo do tempo, um monumento quase histórico. Em 2000, a italiana Rizzoli Libri adquiriu 100\% das ações da Flammarion.
} 
seroterapia do cancro, que Hervé Watier (1961-...), da Université de Tours, se começa a interessar por Héricourt e pelo seu colaborador e amigo Charles Richet, vindo a ser orientador da primeira tese de doutoramento sobre o autor, com o título: Dr. Jules Héricourt (1850-1938): découverte de la sérothérapie, affaire Dreyfus, hygiène sociale: parcours d'un médecin engagé dans la IIle République (SUDOC, 2021), elaborada por Yves-Marie Lahaie (1984-...) ${ }^{10}$.

Sendo a assistência sanitária um determinante clássico da saúde pública ${ }^{11}$, J. Héricourt está preocupado com o papel do médico na irradicação ou mitigação das doenças atenuadas. Aliás, o autor escreve outro livro na mesma coleção da Bibliothèque de Philosophie Scientifique - L'Hygiène Moderne (1907) - sendo apresentado como uma obra totalmente nova, e que nada tinha a ver com os clássicos tratados de higiene. Para o efeito, foram apresentadas aos leitores um conjunto de ideias gerais capazes de os orientar, que seriam a garantia para a solução de todos [sic] os seus problemas relativos à conservação e proteção saúde.

Este estudo, que se apresenta neste artigo, analisa as ideias de J. Héricourt relativamente à transmissibilidade internacional das doenças epidémicas e o modo de mitigar as suas cadeias, através da intervenção do médico de bordo. Apoia-se, na essência, na sua obra Les Frontières de la Maladie, nomeadamente na Défense internationale contre las maladies épidémiques, et systémes quarantenaires.

\section{Da peste bubónica}

Até meados do século XIX, a fome batia repetida e violentamente sobre as populações europeias. As doenças epidémicas irrompiam frequentemente $\mathrm{e}$ juntavam-se às misérias provocadas pela escassez de alimentos, provocando consideráveis perdas de vidas humanas, particularmente crianças (WHO, 1999). Como se não bastasse, a este equilíbrio instável justavam-se guerras que, para além dos mortos que geravam, a deslocação dos exércitos, ao encontro uns de outros, era suficiente para alterar as condições locais, gerando mais fome e propagando pandemias. A tudo isto, somavam-se as precárias condições higiénicas.

A partir da última década do século XIX, assiste-se a uma progressão mais rápida da esperança média de vida à nascença. Em França, por exemplo, entre 1800-

\footnotetext{
${ }^{10}$ A tese de Lahaie ganhou, em 2017, o Prix de thèse d'histoire de la médecine Georges Robert, na categoria Prix des thèses et mémoire - mention sciences médicales, prémio atribuído pela Société française d'histoire de la médecine (SFHM, 2021). Numerosos documentos relativos a Héricourt foram legados à Fondation Rabelais, em Tours, e depositados na Bibliothèque universitaire de médecine, Émile-Aron da Faculté de Médecine da Université de Tours.

${ }^{11}$ Lalonde (1974) virá mais tarde a analisar esta questão dos determinantes de saúde e construir um modelo que passou a ser clássico em saúde pública. Segundo o autor, o nível de saúde de uma comunidade é determinado pela interação de quatro variáveis: a) a biologia humana; b) o meio ambiente (contaminação física, química, biológica, psicossocial e sociocultural; c) o estilo de vida (comportamentos de saúde); e d) o sistema de assistência sanitária.
} 
1880 este indicador passou de 34,0 para 41,8 anos, cifrando-se em 1960 em 67,2 $\operatorname{anos}^{12}$ (Morichau-Beauchant, 1971). O crescimento da população justifica-se não tanto pelo aumento do número de nascimentos, mas mais pela redução da mortalidade.

Vários fatores contribuíram para reduzir a mortalidade, no período que Terris (1982) designa de "primeira revolução epidemiológica": com melhoria das condições socioeconómicas e as medidas específicas de saúde pública, estas doenças foram quase vencidas nos países desenvolvidos. Tal alcance foi conseguido porque a maior parte da morbilidade e mortalidade por doenças infeciosas desta etapa (época bacteriológica da saúde pública) obedecia a fatores ambientais desfavoráveis, tais como a contaminação da água para beber, ausência de sistemas de saneamento, sobrelotação em habitações insalubres, consumo de alimentos contaminados, proliferação de insetos e de roedores, alimentação deficiente, débeis condições higiénicas nos locais de trabalho e em casa e, em grande parte, grande iliteracia da população relativamente a assuntos da saúde (Salleras, 1988).

A peste é uma doença infeciosa causada pelo bacilo Gram-negativo Yersinia pestis $^{13}$. Existem três formas principais: peste bubónica, peste septicémica e peste pneumónica. O continente europeu tem uma longa história, com evidências desta doença que datam da Idade da Pedra. A primeira epidemia de peste identificada na Europa data do século VI. Reaparece, depois, na Idade Média, conhecida com a designação de peste negra ${ }^{14}$, dizimando cerca de 25 milhões de vítimas, correspondendo a 1/4 da população da Europa ocidental (Morichau-Beauchant, 1971).

No final do século XIX, o flagelo infecioso não era já a peste, mas a cólera. Rossiter (1933), por exemplo, na sua obra já não se refere à peste, mas inclui a cólera. No entanto, a Europa ainda experimentou surtos de peste durante a Terceira Pandemia (1894-1945) ${ }^{15}$, quando já tinha sido considerada extinta há cerca de meio século. Em 1879, eclodiu um surto nas margens do rio Volga, perto de Astrakhan, na Rússia, da qual resultaram aproximadamente 400 mortos. Mais distante, em

\footnotetext{
${ }^{12}$ Atualmente, a esperança média de vida ao nascer, em França, cifra-se nos 79,2 anos para os homens e nos 85,3 anos para as mulheres (INED, 2021).

${ }^{13}$ Alexandre Yersin (1894-1945) descobriu em 20 de junho de 1894, em Hong Kong, o agente infecioso da peste bubónica: Pasteurella pestis rebatizada, em 1967, de Yersinia pestis. Isolou os bacilos em ratos, os principais propagadores da epidemia. De facto, comprovou-se que a doença é transmitida para o ser humano pela picada de pulgas (Ordem Siphonaptera) infetadas na picada de ratos mortos. No ano seguinte, Yersin desenvolveu soros antipestosos, quanto estava no recém-criado Institut Pasteur.

${ }^{14}$ Esta designação advém do facto da peste bubónica provocar hemorragias subcutâneas, formando-se equimoses azul-escuras ou negras e, ainda, a cerca de 50\% dos casos serem fatais (DK, 1996).

${ }^{15}$ Antigos estudos de ADN identificaram $Y$. pestis, o agente etiológico da Terceira Pandemia, como a causa das pandemias de peste anteriores: a Primeira Pandemia (séc. VI-VIII) e a Segunda Pandemia (séc. XIV-XIX).
} 
Cantão, na China meridional, em 1894, a peste provocou 180.000 mortes $^{16}$ (Morichau-Beauchant, 1971), espalhando-se globalmente no final do século XIX por via marítima (Proust, 1897, p. V). O controlo sanitário nas fronteiras constituía, como ainda acontece atualmente ${ }^{17}$, uma preocupação acrescida para as autoridades de saúde pública. Outros focos se registaram: Bombaim, na Índia ${ }^{18}$, em 1896; Toamasina $^{19}$, em Madagáscar e Djeddah, na Arábia Saudita, em 1898; Japão, Portugal $^{20}$, Reunião (Departamento Francês ${ }^{21}$ ), Manchúria, Havai, Brasil, Argentina e Egito, em 1899 (Chevanllier, 2015; Morichau-Beauchant, 1971) ${ }^{22}$.

Durante as três pandemias, distintas estirpes de $Y$. pestis foram introduzidas na Europa, causando epidemias de peste, incluindo a peste negra (1346-1353). As duas primeiras estirpes consideram-se extintas. Recentemente foram identificadas as primeiras estirpes conhecidas de $Y$. pestis na Europa, que datam da Idade da Pedra (Bramanti, Dean, Walløe, \& Stenseth, 2019).

\section{A quarentena de Frioul}

Em França, a história da quarentena de 1901, de peste bubónica no lazareto de Frioul, é-nos contada pelo escritor e jornalista Jean Auguste Bertot (1856-1934) (Bertot, 1902). Em setembro de 1901, a Revue Générale des Sciences Pures et Appliqueés, sob a direção do seu criador Louis Frédéric Olivier (1854-1910), organiza o $13 .^{\circ}$ cruzeiro de trabalho e lazer no Mediterrâneo, fretando o navio

16 Adrien Proust (1834-1903), médico e higienista da Faculté de Médecine de Paris e membro da Academie de Médecine, refere 100.000 vítimas, pese embora considere que a pandemia passou quase despercebia, porque “il ne s'agissait il est vrai que de Chinois” (Proust, 1897, p. V).

${ }^{17}$ Cfr. SNS24 (2021).

${ }^{18}$ Provocando 13 milhões de mortos (Morichau-Beauchant, 1971).

${ }^{19}$ Frequentemente chamada de Tamatave.

${ }^{20}$ Os primeiros casos surgiram em agosto de 1899 , no Porto, manifestados num grupo de carregadores do porto (Pereira, 1952). A primeira reação da população foi a de êxodo, em massa, expondo o restante território ao contágio. O Governo decretou o isolamento da cidade por um cordão sanitário, provocando um protesto quase geral da população. Seguiram-se cortes no abastecimento à cidade, uma vaga de desemprego, ceticismo e grandes ajuntamentos públicos, que precipitaram o Porto e o país para um cenário de caos que permitiu uma maior propagação desta doença (Pontes, 2012). Na ocasião, levantou-se uma campanha contra Ricardo Jorge, médico diretor dos serviços de higiene da cidade do Porto, em parte apoiada pela imprensa, acusando-o de antipatriota e inimigo da sua terra, colocando em dúvida a sua competência como bacteriologista e a veracidade do seu diagnóstico. Chamados especialistas estrangeiros ao cenário, foi confirmado o diagnóstico de Ricardo Jorge e manifestada a admiração pelo modo como descobriu a doença (Pereira, 1952). A epidemia da peste arrastou-se até fevereiro de 1900. Só no Porto, a peste atingiu 320 pessoas, provocando entre 112 a 182 vítimas mortais (Maia, 2020, 18 de março; Pereira, 1952), mas calculando-se que tenha escapado ao conhecimento médico cerca de 100 casos.

${ }^{21}$ Em França, os últimos casos remontam a 1920, afetando uma centena de pessoas em Paris e alguns casos assinalados em Marselha, entre as duas guerras, e sete casos em Ajaccio, em 1945 (Morichau-Beauchant, 1971).

22 O continente americano é afetado pela primeira vez em 1900, penetrando até Asuncion, Califórnia. 
transatlântico Senegal ${ }^{23}$ da Compagnie des Messageries Maritime ${ }^{24}$, sob o comando de A. Charbonnel, acompanhado de 62 membros da tripulação. Piotrowsky era o médico de bordo. Previa-se que o historiador Charles Diehl (1859-1944) ministrasse palestras durante a viagem. O navio deveria levar os passageiros (pessoas das ciências e das letras, das artes e do clero, da medicina e da magistratura, incluindo Raymond Poincaré, futuro Presidente da República Francesa entre 1913-1920) aos portos de Levante (Síria, Palestina, Líbano) através das ilhas de Rodes, Chipre, Creta e Malta.

O Senegal saiu do cais de Joliette, em Marselha, com os seus 174 passageiros, em 14 de setembro (sábado) e fundou âncora em Ajaccio, na Córsega, para uma visita à cidade e à casa natal dos Bonaparte. O segundo contramestre - Marius Febre - estaria doente há dois dias. O médico do navio terá pedido ao médico Chauffard que examinasse o paciente: um homem robusto de 33 anos, que no dia anterior apresentava sinais de mal-estar estomacal, e naquele momento estava com febre "vivaz" e um "leve inchaço das glândulas inguinais" à esquerda. No entanto, ele quase não se sentira mal, não estava na cama e permanecera misturado com a demais tripulação. $\mathrm{O}$ tripulante há muito que fazia parte da tripulação deste barco (Bertot, 1902).

Isso levantou suspeitas aos dois médicos, além de Jules Bucquoy (1829-1920), quando interpelado. Aliás, será precisamente este médico J. Bucquoy, como veremos, que virá a fazer na Académie de Médecine um relato médico detalhado da peste a bordo do Senegal e da quarentena em Frioul. Pediu-se a Demons, um médico cirurgião de Bordeaux, que examinasse cuidadosamente o paciente, não tendo este encontrado lesões superficiais que explicassem a adenite.

$O$ caso era, portanto, suspeito, mas supondo-se que não fosse um caso de peste confirmado. J. Bucquoy questionava-se sobre o que deveria ser feito e como se deveria proceder relativamente à viagem.

Foi, então, pedido isolamento imediato e injeção de soro antipestoso. Mas, não havia soro a bordo, embora o Senegal tivesse estado de serviço em Alexandria, um

${ }^{23}$ Contruído em 1870. Ficou danificado por explosão, quando em 1913 atingiu uma mina à entrada de Esmirna (Grécia), sendo considerado irreparável, seguindo para demolição. Com um comprimento de $125 \mathrm{~m}$ e a largura de $10,06 \mathrm{~m}$, tinha $2425 \mathrm{t}$ de porte bruto e deslocava até $4882 \mathrm{t}$. Os motores, de 3 cilindros debitavam até $1900 \mathrm{cv}$ (2400 cv a partir de 1889), com uma velocidade de cruzeiro de 13 nós. Capacidade de 222 passageiros em cabine e possibilidade de transportar até 1200 pessoas entre conveses. Forro do casco em ferro, 1 hélice, 1 chaminé, 3 mastros com mastro de proa; proa direta e longa; telhado de popa longo; construído de acordo com os planos do engenheiro Vésigné (Bois, 1992, Ramona, 2021b).

${ }^{24}$ Comummente conhecida de MesMar, foi uma empresa francesa de transporte marítimo, fundada em julho de 1851. A companhia encerrou suas operações em 1977, fundindo-se com a Compagnie Générale Transatlantique, conhecida no exterior como French Line, para criar a Compagnie Générale Maritime, que se dedica exclusivamente ao transporte marítimo de cargas. Foi comprada depois pela Compagnie Maritime d'Affrètement, constituindo, atualmente, a CMA CGM, SA. 
porto infetado, onde a peste ressurgira no final de agosto e onde o navio ficara os dois dias legais ${ }^{25}$. A solução para a segunda parte da questão foi dada pelo capitão e pelo médico de bordo. Tendo a bordo um paciente com adenite, qualquer que fosse a sua natureza, todos os portos da Turquia estariam encerrados. Mediante este facto convincente, iriam expor-se a uma navegação prolongada, doravante sem objetivo, e finalmente a uma provável quarentena, num lazareto turco, sem conhecer as condições. O mais sensato seria o Senegal dar meia-volta e dirigir-se o mais rapidamente possível a um porto francês para desembarcar o paciente. Todos os passageiros entenderam que se estava diante de uma fatalidade que se deveria suportar, e que o melhor seria sair dessa má situação o mais celeremente, sem se exporem a imprevistos.

No final da tarde de 16 de setembro (segunda-feira), avistando-se a ilha de Lipari (Sicília), o comandante fez o Senegal dar meia-volta, pela ocorrência do caso suspeito de peste declarada a bordo. O comandante informou os turistas, através de um aviso manuscrito, que era obrigado a dirigir-se ao primeiro porto francês para desembarcar o paciente e que poderia ser necessária uma quarentena na Turquia.

O Senegal não dispunha, também, de microscópio. Louis F. Olivier pareceulhe que o paciente já se encontrava melhor, por este se ter levantado e conversado na porta do seu camarote, pelo que a viagem seria retomada quando $\mathrm{M}$. Fabre fosse desembarcado em Ajaccio. Talvez por isso, não houve pânico a bordo do Senegal, porque não se acreditava que de peste se tratasse.

À noite, uma interessante conferência dada por C. Diehl sobre os países que não se deveriam visitar, ocupou as mentes dos passageiros, e no dia seguinte, terça-feira, o Senegal estava no Estreito de Bonifácio, onde o comandante pôde avisar a gestão da Messageries Maritimes, de que tinha um caso suspeito de peste a bordo e que o barco estava a regressar a Marselha. O nevoeiro intenso na manhã de quarta-feira 18, terá atrasado a chegada em 6 horas, chegando o navio às $11 \mathrm{~h}$. Puxado por um rebocador, entrou num pequeno porto em Frioul na manhã do dia 18 (quarta-feira).

Por volta das $13 \mathrm{~h}$, o médico Jacques, encarregou-se da visita aos passageiros, examinou o paciente e colheu líquido bubónico para exame bacteriológico. Nas 48 h seguintes, o capitão do Senegal procedeu à desinfeção das instalações ocupadas pela tripulação. Estas e os próprios homens foram lavados com sublimação numa estufa. Nenhuma outra nova medida foi prescrita.

Enquanto se aguardavam os resultados dos exames, os passageiros permaneceram no Senegal nas águas de Frioul, nas proximidades de outro barco da Messageries que acabara de encerrar a quarentena dois dias depois - o Ernest-

\footnotetext{
${ }^{25}$ A J. Bucquoy, terão sido relatados, naquela época, 11 casos de peste em Alexandria, incluindo 6 mortes, sem que nada fosse oficial.
} 
Symons - um grande transatlântico, que voltara do Extremo Oriente. As ilhas percebem-se nuas, sem arbustos e sem alma vivente. A cidade parecia devastada por uma terrível epidemia, que matara todos os seus habitantes, mantendo-se as janelas fechadas, pois ninguém restaria para as abrir.

Uma chalupa sanitária atracou no Senegal, com a visita do médico Catelan, diretor do serviço de saúde de Marselha, acompanhado pelo médico Gauthier, responsável pelo laboratório de bacteriologia. A primeira pesquisa de esfregaço revelou bacilos da peste, mas em número reduzido e mal caraterizados. Procuraramse, então, ratos vivos.

Além disso, a questão não era tão clara, mesmo à chegada a Frioul. Jacques, que havia tratado pacientes da peste no Laos, e já tinha, como o seu colega Gauthier, contraído a peste, não teria ele mesmo manifestado dúvidas quanto à natureza da doença. Mas era, de facto, a peste. M. Fabre foi desembarcado, acenando aos restantes embarcados, aumentando o ceticismo. O paciente foi transportado para o Hôpital Caroline, na ilha de Ratonneau. Recebeu soro antipestoso, mas a febre e o delirium continuaram e aumentaram, até que na noite de sábado para domingo veio a óbito.

A questão a resolver era perceber a origem da praga que o paciente tinha contraído. Tendo saído de Marselha, porto ileso, depois de uma estadia de 17 dias e regressando de Alexandria, apontava-se a possibilidade de ter contraído a doença neste último porto, tendo a incubação da peste apenas a duração de alguns dias. $\mathrm{O}$ caso ficou resolvido no dia seguinte ao desembarque no lazareto. Quando foi aberta a roupa suja, foram encontrados vários ratos mortos portadores do bacilo. Eles tinham contaminado o navio atracado no porto de Alexandria. Pesquisas bacteriológicas revelaram, também, que ratos vivos, embora aparentemente com boa saúde, estavam todos infetados com o bacilo da peste. A mesma observação já havia sido feita para os ratos do Laos. Ou seja, um barco saindo de um porto não infetado foi obrigado a fazer, de início, uma quarentena, o que normalmente não era feito até ao seu retorno (Bertot, 1902).

Os passageiros permaneceram no Senegal até sábado, pela demora do Conselho de Saúde em preparar as condições para acolhê-los. No dia seguinte à chegada, foi declarado novo caso de peste na tripulação. $O$ paciente foi desembarcado, conduzido ao hospital de Ratonneau e imediatamente tratado com soro, vindo a recuperar.

Somente na sexta-feira, 20 de setembro, os passageiros desembarcaram, para entrarem em quarentena no lazareto de Frioul, mas sem nenhum serviço organizado para os receber adequadamente. Foram alojados em quartos individuais, destinados a senhoras que viajavam sozinhas e a casais, e em dormitórios, para os demais passageiros, cada um com 22 camas. As refeições fizeram-se em conjunto. Foi 
afixado um regulamento com 77 artigos, datado de 1822, punindo qualquer incumprimento com pena de morte, e um regulamento local de 1835, com 558 artigos, considerado por Jean A. Bertot ridículo, quando não era odioso.

Catelan fora a favor da inoculação de soro nos passageiros, mas não havia soro fresco em Marselha ou em Frioul. Restava um pouco que sobrara de Laos: há três dias que o esperavam de Paris, tendo chegado somente no domingo, 22 de setembro. Nessa mesma noite, iniciaram as injeções nos passageiros voluntários com o que sobrara do soro antipestoso e, para dar um bom exemplo, os médicos viajantes no cruzeiro foram os primeiros a serem inoculados. Apenas cerca de 10 refratários recusaram o soro e vários tiveram efeitos colaterais.

A tripulação do Senegal, que estava ao largo, foi transbordada, após a desinfeção e inoculação, para o cruzador costeiro Ortegal, em 25 de setembro (quarta-feira), que atracara ao seu lado. Raymond Poincaré moveu influência junto do prefeito de Bouches-du-Rhône (Provence-Alpes-Côte d'Azur), que visitava a ilha, para que as pessoas na faixa dos 40 anos de idade pudessem viajar para a ilha de Pomègues, a maior e mais interessante do arquipélago de Frioul.

Foram implementadas medidas de desinfeção, primeiramente na roupa suja, mas foi algo considerado opcional. Os baús e bagagens, cheios de objetos pessoais, foram borrifados com uma bomba junto das camas.

O último dia da quarentena, de 7 deles completos em vez dos 10 dias legais, foi 26 de setembro (quinta-feira). Alguns arrependeram-se de deixar a ilha, mas os custos da quarentena, segundo as leis, eram da responsabilidade dos quarentenários.

\section{Do controlo epidémico}

Na sessão de 29 de outubro de 1901 da Académie de Médecine, J. Bucquoy fez um relato médico detalhado da peste a bordo do Senegal e da quarentena em Frioul (Bucquoy, 1902). O médico, que fora passageiro, foi muito crítico acerca da falta dos serviços mínimos e, principalmente, pela falta de desinfeção imediata dos passageiros e das respetivas bagagens.

Após a saída antecipada da quarentena, nenhuma vigilância sanitária tinha ocorrido. J. Bucquoy observou as seguintes falhas sanitárias: a) embarcar num navio com vigilância sanitária insuficiente; $b$ ) ausência de soro antipestoso a bordo do Senegal; c) ausência de soro no lazareto para a tripulação e passageiros; d) manutenção de passageiros no barco contaminado por vários dias e a tripulação por uma semana; e) falta de manutenção e bom funcionamento do lazareto, principalmente após a lamentada passagem por Laos; f) falta de medidas de desinfeção rápidas. Bucquoy (1901) considerou que os regulamentos, tão bons que eram, tinham valor e eficácia apenas pela forma como eram aplicados, por isso, 
conclamou a Academia a intervir junto às autoridades para exigir as reformas necessárias.

Ora, é precisamente neste contexto que Héricourt considera que as medidas à época, assim como as do passado, eram teoricamente insuficientes e, na prática, absolutamente ilusórias na defesa internacional contra as doenças epidémicas, pois, de acordo com o modo real que elas são executadas, teria de considerá-las tão grotescas quanto vaidosas, e rejeitá-las em bloco, sem discussão. Para o provar, invoca o reporte que L. Lortet ${ }^{26}$ apresentara na Académie de Médecine, em 16 de junho de 1904, com os factos que, com J. Tessier ${ }^{27}$, terá testemunhado, acerca da aplicação dos regulamentos em Frioul, em 1902-1903.

Nos navios Portugal $^{28}$ e Senegal da MesMar, quando não havia pacientes, os passageiros recebiam uma camisola, um par de meias e um lenço de bolso para leválos à estufa. Porém, não se levava à desinfeção a roupa da tripulação, que convivera várias semanas em plena promiscuidade com centenas de sírios, nem eram desinfetados os espaços do navio, que continham toda a poeira do Baixo-Egito e as galerias escavadas por ratos.

À época, era distribuído um passaporte sanitário. Em Lyon, todavia, tal documento era desconhecido como sendo destinando a permitir seguir os passos dos viajantes e a garantir o seu estado de saúde. Em Marselha, a vigilância da saúde costumava ser atrasada por várias horas, durante as quais passageiros saudáveis ficavam expostos à contaminação, no caso de haver suspeita de casos positivos.

Loret considerou que os casos duvidosos, de difícil diagnóstico, ou mesmo esquivos pelo exame mais ou menos rápido do médico, eram mais numerosos do

${ }^{26}$ Louis Charles Émile Lortet (1836-1909) foi médico, botânico, zoólogo e egiptólogo. Foi decano da Faculté de Médecine de Lyon (1877-1906) e diretor do Musée d'Histoire Naturelle de Lyon (18771906). Fez várias expedições científicas e zoológicas ao Médio Oriente (Síria, Líbano, Egito). Foi membro fundador da Société de Géographie de Lyon (DBpedia, 2021) e da Académie Nationale de Médecine, de Franca. Na missão científica à Síria, encarregue pelo Ministère de l'Intruction Publique francês, elaborou a sua história, que veio a ser publicada na editorial Tour. O pintor francês Étienne Antoine Eugène Ronjat (1822-1912), com base em fotografias, imortalizou a história da Síria com a gravura Maisons et habitants de Jérico (Meisterdrucke, 2021).

${ }^{27}$ Louis Anne Marie Joseph Teissier (1851-1926), médico e antropólogo francês, doutorou-se, em 1876, na Faculté de Médecine de Lyon. Foi nomeado médico de hospital em Lyon, em 1877 e, em 1884, é professor de patologia interna em Lyon. Membro da Académie Nationale de Médecine, de Franca (BM, 2021).

${ }^{28}$ Construído em 1886. Em outubro de 1914, ficou encalhado no Mar Negro pelo fechamento do estreito, sendo depois bombardeado em Odessa por torpedeiros turcos. Em 1915, foi requisitado, ao serviço da marinha russa, com uma tripulação da marinha francesa, como navio-hospital. Em 30 de março de 1916 foi torpedeado e afundado enquanto estava perto do ancoradouro de Batoum, no cabo de Pathie, Mar Negro, pelo submarino alemão U33. Exibia marcações com uma cruz vermelha. Houve 115 vítimas mortais. Com um comprimento de $140,2 \mathrm{~m}$ e a largura de $14 \mathrm{~m}$, tinha $4468 \mathrm{t}$ de porte bruto, deslocando até 7720 t. Os seus motores, com uma alternativa de expansão tripla de 4 caldeiras, debitavam $4800 \mathrm{cv}$, a uma velocidade de 16,5 nós, com uma única hélice. Ostentava dupla chaminé. Capacidade de 125 passageiros em primeira classe, 90 em segunda e 700 em terceira (Bois, 1992; Ramona, 2021a). 
que se poderia pensar. Como era o caso da peste que, às vezes, se manifestava pelo vago congestionamento ganglionar, e outras por inflamações pulmonares de aparência comum, com expetoração que, entretanto, fervilhava de bacilos da peste, muito mais perigosa que os bubões da peste, que pouco seriam de temer. Os regulamentos, embora tivessem sido rejuvenescidos no papel, continuavam a ser executados de acordo com os erros antigos. Os navios mantinham uma qualidade sanitária deplorável, com latrinas de frente, habitadas por tripulações e emigrantes.

Com estas condições, Héricourt concluiu, ironicamente, que se na França não havia peste nem cólera, era porque os micróbios colocavam boa vontade nisso, porque os circuitos eram excecionalmente favoráveis a eles. $\mathrm{O}$ autor prossegue com uma análise das medidas logicamente concebidas que J. Teissier propôs, supondo que eram rigorosamente observadas, sem qualquer falha material ou moral do pessoal.

Em primeiro lugar, o passe sanitário ${ }^{29}$. Nos portos mediterrâneos, todos os passageiros provenientes de territórios contaminados, ou transportados em navios onde um caso de doença contagiosa exótica se desenvolvera durante a travessia, deveriam ser portadores deste documento, medida que deveria ser amplamente aplicada, sob controlo rigoroso das autoridades competentes.

Se o navio apresentasse casos comprovados de doenças infeciosas exóticas como, por exemplo, peste, todos os passageiros, antes de receberem o seu passaporte, deveriam ser submetidos individualmente a uma inspeção sanitária completa. No caso de um passageiro examinado ser reconhecido em bom estado de saúde, deveria ser obrigatório sistematizar a desinfeção da sua pessoa e de toda a sua bagagem em perfeitas condições. Paralelamente, deveria ser facultada a possibilidade de inoculação preventiva do soro antipestoso, com a possibilidade de o passageiro recusar ou aceitar. O barco deveria ser submetido, na continuação, à desinfeção completa da carga e dos porões.

$\mathrm{O}$ internamento deveria ser reservado para passageiros com suspeita de possível contaminação, por terem contactado mais diretamente com um paciente positivo ou que apresentasse algum sinal mais suspeito. Para o efeito, o paciente seria internado num pavilhão de observação antes de se proceder ao internamento propriamente dito.

\footnotetext{
${ }^{29}$ Sublinhe-se que, passados 120 anos, o passe sanitário continua a ser uma medida em saúde pública. No âmbito da pandemia covid-19, foi criado na União Europeia o European Union Digital Certificate. Consiste num passe sanitário europeu, com apresentação digital ou em suporte papel, que comprova que uma pessoa recebeu o esquema de vacinação completo contra o Sars-Cov-2, que se recuperou da covid-19 nos últimos 6 meses ou recebeu um teste negativo nas últimas 48 horas (teste de antigénio TRAg) ou 72 h (teste TAAN). O certificado tem como objetivo facilitar a circulação e segurança das pessoas dentro e fora de cada Estado-Membro, bem como o acesso a determinados espaços e eventos. Ele pode ser usado em todos os Estados-Membros da União Europeia e nos países do Espaço Schengen (Islândia, Liechtenstein, Noruega e Suíça) (ePortugal, 2021).
} 
A solução do problema da transmissibilidade na fronteira poderia ser facilitada se a administração de saúde tivesse acesso às observações clínicas dos médicos marítimos $^{30}$. Estes poderiam ser investidos de maior autoridade, que garantisse a sua independência, de modo a tornarem-se verdadeiros colaboradores ou agentes da administração de saúde.

Todas as medidas anteriores partiam de um diagnóstico positivo da doença. Qualquer pessoa reconhecida como não doente, ou que não tivesse tido contacto com algum doente, seria admitida à livre circulação, sob condição de ser portador de passe sanitário especial destinado às suas viagens sucessivas.

O problema é que, para Héricourt, não se via quem se opusesse à livre circulação de pessoas que sofressem de formas latentes e muito atenuadas de doenças exóticas; ou apenas do período prodrómico, no curso de incubação das doenças em questão, que dura de dois a seis dias ${ }^{31}$. Um indivíduo picado naquele dia por uma pulga da peste, receberia o seu passe sanitário no dia seguinte, ainda antes que a inflamação linfonodal ocorresse, ou de outro que estaria a gerar uma broncopneumonia infeciosa. Questiona-se como se poderia alcançar ou reter os pacientes coléricos ao diagnóstico, que se sentiam admiravelmente bem, com uma ou duas evacuações diárias, além de abundantes em germes contagiosos. O autor nota que alguns pacientes escondiam dos médicos cuidadosamente algum mal-estar para que não ficassem privados da sua liberdade.

Mesmo quanto aos passes sanitários, parece-lhe ingénuo pensar que os viajantes obedeciam às suas prescrições. Assim, os infetados latentes ou atenuados conduziriam os seus micróbios, semeando-os em todo o tipo de espaços públicos durante as suas viagens, e voltar-se-ia a lamentar as velhas quarentenas, que retinham todos mais tempo do que as incubações mais longas. Ainda assim, seria de se temer, nessa prática de eras passadas, que a evolução sucessiva dos casos latentes estivesse justamente na sua plenitude no momento em que terminava a quarentena regulatória.

Em síntese, parece evidente que nenhuma rede, esticada quando os barcos chegavam, ou quando os trens passavam, poderia ter uma malha tão estreita que as doenças atenuadas não a pudessem transpor. Essas malhas retinham apenas os

\footnotetext{
30 Atualmente, a assistência médica a bordo dos navios é regulada pela Diretiva 2007/30/CE do Parlamento Europeu e do Conselho, de 20 de junho de 2007, que altera a Diretiva 89/391/CEE do Conselho, as suas diretivas especiais e as Diretivas 83/477/CEE, 91/383/CEE, 92/29/CEE e 94/33/CE do Conselho, tendo em vista a simplificação e a racionalização dos relatórios relativos à aplicação prática, acompanhada do Regulamento (CE) n. ${ }^{\circ}$ 1882/2003 do Parlamento Europeu e do Conselho de 29 de setembro de 2003, e Regulamento (CE) n. ${ }^{\circ}$ 1137/2008, do Parlamento Europeu e do Conselho de 22 de outubro de 2008. Para além disso, a França dispõe, como outros países, de um Centro de Consultas Médicas Marítimas (Pujos, Roux, Tabarly, \& Ducassé, 2013).

${ }^{31}$ Incubações de poucas horas ou de oito ou mais dias são incomuns.
} 
doentes, e a característica dos pacientes que Héricourt considera é justamente a de não terem a aparência deles.

Havia, portanto, que se resignar a praticar apenas medidas sanitárias muito imperfeitas, muito incompletas, mesmo que fosse possível realizá-las completa e perfeitamente. Héricourt pensa que seria melhor prescrevê-las da forma mais humana e menos incómoda possível. Ora, é precisamente neste ponto que, segundo o autor, se deveria voltar para a importância do papel do médico de bordo. Este poderia ter o ónus de participar no sistema de proteção dos portos e dos postos de fronteira. Em vez de unicamente perceber e tratar as doenças, o médico deveria, regularmente, observar e vigiar a todo o momento o estado de saúde dos passageiros $^{32}$.

Um novo regulamento deveria incluir, para todos os passageiros, um exame médico diário, que permitisse ao médico observar as menores perturbações que ocorressem durante a viagem e interpretá-las com pleno conhecimento dos factos. Ao médico de bordo deveria ser-lhe dado tempo para apoiar o seu diagnóstico, com provas bacteriológicas, e da emissão, à atracagem, de atestados de bom estado de saúde, em vez dos então atestados lavrados com um exame realizado com pressa, sem controlo de qualquer espécie, e com o objetivo indisfarçável de desfazer-se dessa tarefa árdua.

Assume-se que o exame diário que propõe poderia, à primeira vista, ser considerado um incómodo. Mas Héricourt considera que tal procedimento seria muito rapidamente aceite. Os próprios passageiros apressar-se-iam a procurar o médico, não só porque saberiam que essa era a condição para afastamento de obstáculos no momento do desembarque, mas também porque, sabendo que procedem de um ambiente realmente perigoso, entenderiam o seu interesse de serem avisados dos primeiros sinais do mal da peste ou da cólera que, uma vez tratada desde o início, podia evoluir nas suas formas mais benignas.

Nos primeiros dias, a visita ao médico poderia basear-se numa simples entrevista, numa conversa banal. A intimidade ganhar-se-ia gradualmente, entre viajante e supervisor de saúde. O médico, longe de procurar desmascarar doenças ocultas, só teria que receber as confidências dos seus passageiros, que seriam os primeiros a chamar a atenção para os menores problemas da sua saúde.

Héricourt é bem claro: antes de mais nada, seria uma questão de tato e sensibilidade por parte dos médicos dos paquetes. Para tamanha realização, seria

\footnotetext{
32 Atualmente, a França dispõe da Societé Française de Médecine Maritime, com os objetivos de promover a higiene e a saúde no ambiente marítimo, de promover e desenvolver conhecimentos médicos sobre o meio marítimo, o ensino e as especificidades do exercício médico no meio marítimo, de reunir médicos, investigadores e todos os profissionais de saúde interessados ou interessados na medicina marítima e de desenvolver relações com outras empresas de medicina marítima a nível internacional (SFMM, 2021)
} 
necessário que os médicos recebessem formação suficiente, a fim de serem capazes de fazer trabalho sério e proveitoso. Assim, como antes defendido, transformar-seiam, de facto, em colaboradores, ou melhor, em verdadeiros agentes da administração sanitária, e a sua independência, garantiria a sua sinceridade. Caberia ao médico de bordo o direito de atestar o bom ou mau estado de saúde da tripulação, sendo autorizados, em princípio, a prescrever a franca entrada no porto, se a saúde do navio nada tivesse deixado a desejar durante a travessia.

Exige-se, por isso, uma mudança de atitude, para passar de um médico terapeuta, que apenas é chamado em caso de doença, para prescrever medicamentos, ao que é, também, higienista ${ }^{33}$ responsável por zelar pela saúde dos membros de uma comunidade, o observador designado para registar os primeiros distúrbios, procurar a sua natureza e aplicar a essas alterações e à etiologia as soluções mais urgentes. Porque, diga-se a boa voz, a posição temporal que o médico de bordo ocupa dá-lhe privilégio para tratar doenças desde os primeiros sintomas, comparativamente ao seu colega, em terra, que se depara com a doença em plena evolução, ou fica diante do seu fim. Além disso, uma vez avisado pelos primeiros acidentes da existência de um perigo e de um centro infecioso, procurará localizálo e poderá realizar rapidamente as medidas de esterilização mais urgentes.

\section{A concluir}

Em França, em 1901, o surto de peste bubónica no lazareto de Frioul deixou bem claro que a peste não é uma doença totalmente do passado. A história ensinanos que deve existir uma constante vigilância em um determinado número de países. A descoberta de inseticidas e repelentes (e.g., dietiltoluamida - DEET), adicionada à de métodos terapêuticos indicados (e.g., ciprofloxacino, doxiciclina, estreptomicina, gentamicina, levofloxacino) (MSD, 2021) faz com que esta doença não seja, atualmente, uma ameaça para o mundo ocidental.

Todavia, voltou a ocorrer na Argélia e na Líbia há menos de uma década, em locais que ficam a menos de $480 \mathrm{~km}$ das fronteiras europeias. Além disso, a peste está atualmente presente em 11 países do mundo (Bramanti, Dean, Walløe, \& Stenseth, 2019). No processo de globalização que vivemos, caraterizado pelo aumento da mobilidade de pessoas e bens, as doenças podem espalhar-se facilmente de regiões endémicas ou enzoóticas (ou seja, focos e reservatórios) para o resto do mundo num curto período. A peste parece ser um caso de doença reemergente, pela frequência, nos últimos anos, de surtos em países em desenvolvimento de África.

\footnotetext{
${ }^{33}$ Sublinhe-se que o diploma universitário de medicina marítima francês atual prevê o médico de bordo se interesse em toxicologia marítima e higiene a bordo, incluindo na formação a medicina de embarque, para o viajante (antes, durante e depois), a medicina de escala, para além de outros temas (FMSS, 2021).
} 
Héricourt considerava que as medidas da época, para a prevenção da peste, eram teoricamente insuficientes. Mesmo quando aplicadas de modo ideal, não ofereciam capacidade de reter as pessoas que sofriam de doença epidémica. Indivíduos com aparência sã eram formidáveis agentes de contágio. Por isso, o autor propõe uma solução mais prática e eficaz para o problema da defesa contra doenças exóticas: a valorização do passe sanitário e a modificação do papel do médico de bordo, de modo a identificar, precocemente, sinais da doença, evitando que se semeie por todo o tipo de espaços públicos durante as suas viagens e que se voltem a lamentar as velhas quarentenas.

O surto de Frioul recorda-nos que o mundo biológico sempre se digladiou na tentativa de sobrevivência, sendo as pandemias uma expressão antiga e permanente deste conflito interespecífico. Tal recordatória aponta para a necessidade de os países industrializados reagirem prontamente aos surtos de peste, bem como a outras doenças epidémicas, a fim de informar a população e ajudar a combatê-la de modo eficaz ${ }^{34}$.

É este o ponto que Héricourt considera necessário desenvolver: a transformação total da moral em relação ao praticante de medicina, surge-lhe como uma consequência rigorosa do progresso da ciência médica, em geral, e em particular do conceito de doenças atenuadas, e da sua importância primordial na higiene privada e pública.

\section{Agradecimentos}

Agradece-se o convite endereçado pela professora Isilda Teixeira Rodrigues, da Universidade de Trás-os-Montes e Alto Douro, para a elaboração deste artigo. Este trabalho é financiado por fundos nacionais através da FCT - Fundação para a Ciência e a Tecnologia, IP, no âmbito dos projetos UIDB/04312/2020 e UID / CED / 00194/2013.

\footnotetext{
${ }^{34}$ Veja-se, a título de exemplo, o caso de uma criança de 3 anos, em setembro de 2020, ter testado positivo para peste bubónica na China (L'Indépendant, 2020, 29 de setembro) e o da criança com 10 anos de idade que veio a falecer desta patologia, no Colorado, Estados Unidos da América, em agosto do ano seguinte (Salomon, 2021, 09 agosto)
} 


\section{Referências}

Androutsos, G., Karamanou, M., Stamboulis, E., Liappas, I., Lykouras, E., \& Papadimitriou, G. N. (2011). The Nobel Prize laureate - father of anaphylaxis Charles-Robert Richet (1850-1935) and his anticancerous serum. J. Buon, 16(4), 783-786. https://pubmed.ncbi.nlm.nih.gov/22331744/.

Bertot, J. (1902). Au lazaret: souvenirs de quarantaine. Imprimerie Deslis Freres.

BM - The British Museum (2021). Joseph Teissier. The british museum collection. https://www.britishmuseum.org/collection/term/AUTH230821.

Bois, P. (1992). Le grand siècle des messageries martitimes. Chambre de commerce et d'industrie Marseille-Provence.

Bramanti, B., Dean, K. R., Walløe, L., \& Stenseth, N. C. (2019). The third plague pandemic in Europe. Proceedings of the Royal Society B: Biological Sciences, 286(1901), 20182429. https://doi.org/10.1098/rspb.2018.2429

Bucquoy, J. (1901). La peste à bord du "Sénégal", une quarantaine au Frioul. http://sciences.gloubik.info/IMG/pdf/quarantaine au frioul.pdf.

Chevanllier, J. (2015). Une quarantaine de peste au lazaret du Frioul en 1901. Histoire des Sciences Medicales, 49(2), 179-188. https://bit.ly/3228znZ

Daguet, A., \& Watier, H. (2011). $2^{\text {nd }}$ Charles Richet et Jules Héricourt Workshop. $m A b s, 3(5), 417-421$. https://doi.org/10.4161/mabs.3.5.17485.

DBpedia (2021). Louis Charles Émile Lortet. DBPedia. https://bit.ly/3qwvNfu

Delort, R. (1997). Que a peste seja do rato! In J. Le Goff (Apres.), As doenças têm história (pp. 109-126). Terramar.

DK - Dorling Kindersley (1996). Enciclopédia de medicina. Seleções do Reader's Digest.

ePortugal (2021). Request the EU digital covid certificate. https://bit.ly/34KFIFI

FMSS - Faculté de Médecine et des Sciences de la Santé (2021). DU Médecine maritime. https://bit.ly/3FzC0LM

Héricourt, J. (1899). Sérothérapie. Historique, état actuel, biblliographie. J. Rueff, Éditeur. https://iiif.wellcomecollection.org/pdf/b21058271.

Héricourt, J. (1914, fev.). Pouquoi s'arrêtent les épidmémies. La Science et la Vie, 11(4), 277-281. https://bit.1y/3Gy18DX

Hewlett, R. T. (1904). Les Frontières de la maladie: maladies latentes et maladies Atténuées. Nature, 70(100), 1904. https://www.nature.com/articles/070100b0.pdf

INED - Institut National d'Études Démographiques (2021). Espérance de vie. https://bit.ly/3nRB3sz 
L'Indépendant (2020, 29 setembro). Peste noire: après deux morts au mois d'août, un enfant de 3 ans testé positif en Chine qui déclenche le plan d'urgence. L'Indépendant. https://bit.ly/3FvYayv

Lahaie, Y.-M., \& Watier, H. (2017). Contribution of physiologists to the identification of the humoral component of immunity in the $19^{\text {th }}$ century. MAbs, 9(5), 774-780. https://doi.org/10.1080/19420862.2017.1325051

Lalonde, M. (1974). A new perspective on the health of Canadians office of the Canadian Minister of National Health and Welfare. Minister of Supply and Services Canada. http://www.phac-aspc.gc.ca/ph-sp/pdf/perspect-eng.pdf

Maia, A. M. (2020, 18 de março). Que erros se cometeram no combate à peste bubónica, no Porto de 1899? Público. https://bit.ly/3Kc3jj7

Marie, D. (2015). De la serotherapie a l'immunotherapie moderne, un siecle d'avancees medicales. (PhD thesis, Université de Lille). Repositório Institucional da Université de Lille. https://bit.ly/3nuFKIt

Marpeau, B. (2010). Une entreprise éditoriale: la «Bibliothèque de philosophie scientifique» de Flammarion, 1902-1962. Revue d'histoire Moderne et Contemporaine (1954-), 57(4/4 bis), 185-210. http://www.jstor.org/stable/41061544

Meisterdrucke (2021). Häuser und Einwohner von Jericho (Westjordanland). Gravur von E.Ronjat, zur Veranschaulichung der Geschichte des heutigen Syriens, von M.Lortet, Dekan der medizinischen Fakultät von Lyon, beauftragt mit einer wissenschaftlichen Mission durch das Ministeriu). https://bit.ly/3FCbMbE

Monet, J. (2018). Compte rendu de la seance du samedi 17 février 2018. Société Française d'Histoire de la Médecine. https://bit.ly/3rmFtIP

Morichau-Beauchant, J. (1971). La salud en el mundo. Oikos-tau.

MSD - Merck Sharp, \& Dohme (2021). Peste e outras infeções por Yersinia. Manual MSD. Versão saúde para a família. https://msdmnls.co/3qtvhim

Nobel Prize (2021). Charles Richet. Biographical. The Nobel Prize in Physiology or Medicine 1913. https://bit.ly/34VjEZg

Pereira, M. M. (19052). História da medicina contemporânea (Vol. I). Sociedade de Expansão Cultural.

Pontes, D. (2012). O cerco da peste no Porto. (Master's dissertation, Universidade do Porto). Repositório Institucional da Universidade do Porto. https://hdl.handle.net/10216/73326

Proust, A. (1897). La défense de l'Europe contre la peste et la conférence de Venise de 1897. Paris. https://bit.ly/3A1zDAg

Pujos, M., Roux, P., Tabarly, J., \& Ducassé, J. L. (2013). Consultation et régulation télémédicales maritimes. Centre de Consultation Médicale Maritime CCMM. Aide médicale en mer (Ch. 31). Société Française de Médecine d'Urgence. https://bit.ly/3fu0QCh 
Ramona, P. (2021a). Le Portugal. L'Encyclopedie des messageries maritimes. http://www.messageries-maritimes.org/portugal.htm

Ramona, P. (2021b). Le Senegal. L'Encyclopedie des messageries maritimes. http://www.messageries-maritimes.org/senegal.htm

Roques, K. R. V. (1952). Nós e a medicina. Livros do Brasil.

Rossiter, F. (1933). Guia prático da saúde. Sociedade Filantrópica Adventista.

Salleras, L. (1998). Educación sanitaria. Díaz de Santos.

Salomon, D. (2021, 09 agosto). La peste bubonique n'a pas disparu et continue de faire des morts. Le progrés. https://bit.ly/3GBGTW5

Saraiva, A. A. (1926). Sobre a seroterapia especifica da febre tifoide. (PhD's thesis, Universidade do Porto). Repositório Institucional da Universidade do Porto. https://hdl.handle.net/10216/17680

SFHM - Société Française de d'Histoire de la Médecine (2021). Prix de Thèse d'Histoire de la Médecine Georges Robert. https://bit.ly/3rmGsJ1

SFMM - Société Française de Médecine Maritime (2021). Accueil. https://www.medecine-maritime.fr/

SNS24 (2021). Temas da saúde. Prevenção dos viajantes. SNS24. https://bit.ly/3FxI3AJ

SUDOC (2021). Dr Jules Héricourt (1850-1938): découverte de la sérothérapie, affaire Dreyfus, hygiène sociale: parcours d'un médecin engagé dans la IIIe République / par Yves-Marie Lahaie; sous la direction de M. le Pr Hervé Watier. https://www.sudoc.fr/201826712

Terris, M. (1982). La revolución epidemiológica y la medicina social (2. ${ }^{\mathrm{a}} \mathrm{ed}$.). Siglo XXI.

Watier, H. (2009). From the ancient serotherapy to naked antibodies: A century of successful targeted therapies. Medecine sciences: M/S 25(12), 999-1009. https://doi.org/10.1051/medsci/20092512999.

WHO (1999). Manuel de la peste: epidémiologie, répartition, surveillance et lute. $W H O / C D S / C S R / E D C / 99.2$. Organisation Mondiale de la Santé. https://bit.ly/3fvPWMg

Whonamedit (2021). Paul Louis André Kiener. Whonamedit? https://bit.ly/3rq0yDe

WorldCat (2021). Héricourt, J. (Jules) 1850-. WorldCat Identities. https://bit.ly/3AUKc8U 